\title{
Preface of the Book of Proceedings of the Virtual Conference on Chemistry and its Applications (VCCA-2020)
}

A virtual conference on chemistry and its applications (VCCA-2020) was organized online from $1^{\text {st }}$ to $31^{\text {st }}$ August 2020. The theme of the virtual conference was "Research and Innovations in Chemical Sciences: Paving the Way Forward”.

There were 190 presentations for the virtual conference with 300 participants from 50 countries. A secured platform was used for virtual interactions of the participants. After the virtual conference, there was a call for full papers to be considered for publication in the conference proceedings. Manuscripts were received and they were processed and reviewed as per the policy of De Gruyter.

This book, volume 2, is a collection of the eleven accepted manuscripts covering green and sustainable processing.

Ittibenjapong et al reported on Catunaregam tomentosa fruit extracts and AgNPs synthesized from these extracts. Omokpariola and Omokpariola evaluated the health and exposure risk assessment of heavy metals from the usage of rainwater from inhabitants of four oil producing area of Rivers State, Nigeria. Chinda and Chinda investigated the awareness level of social media and how it is used for learning in an era of Corona virus by Chemistry students in tertiary institutions in Rivers State Nigeria. Adeniyi and Giwa determined the concentration of cadmium, calcium, iron, lead, manganese and zinc in the groundwater sources in selected locations in Aboru, Igando, Akesanand Obadore, Lagos, Nigeria. Narod and Narrainsawmy focused on a detailed analysis of the feedback obtained from educators regarding the evaluation of the chemistry curriculum. Lowe and Canal shared their experience in including Polymer science modules to the curriculum at two neighbouring post-secondary institutes and emphasized on educating post-secondary students from different disciplines with polymer science. Constance and Amadou reported on the Influence of calcium oxide on low temperature attack two types of bauxite namely gibbsite and boehmite from Guinea. Odukoya et al studied the volatile components generated from fresh egg, adult female and male of Pestarella tyrrhena and these were assessed using a two-dimensional gas chromatography coupled to time-of-flight mass spectrometry to understand their contribution to odour production. Hernández-Mendoza et al compared the quadrupole inductively coupled plasma mass spectrometry (ICP-QMS) detection and the sector field ICP-MS (ICP-SFMS) for the quantification of elements such as arsenic, cadmium, copper, lead, zinc and uranium in drinking water. Lawrence et al studied the decontamination of laboratory wastewater with an activated carbon derived from maize cob, an agricultural waste, to ascertain its adsorption effectiveness for water treatment. Ejeromedoghene et al presented on the progress in the preparation 
of polymeric ionic liquids via different polymerization reactions and highlight the advances in the fabrications of polymeric ionic liquids based on smart polymeric materials.

I hope that these chapters of this volume 2 will add to literature and they will be useful references for researchers.

To conclude, VCCA-2020 was a successful event and I would like to thank all those who have contributed. I would also like to thank the Organising and International Advisory committee members, the participants and the reviewers.

Prof. Ponnadurai Ramasami 